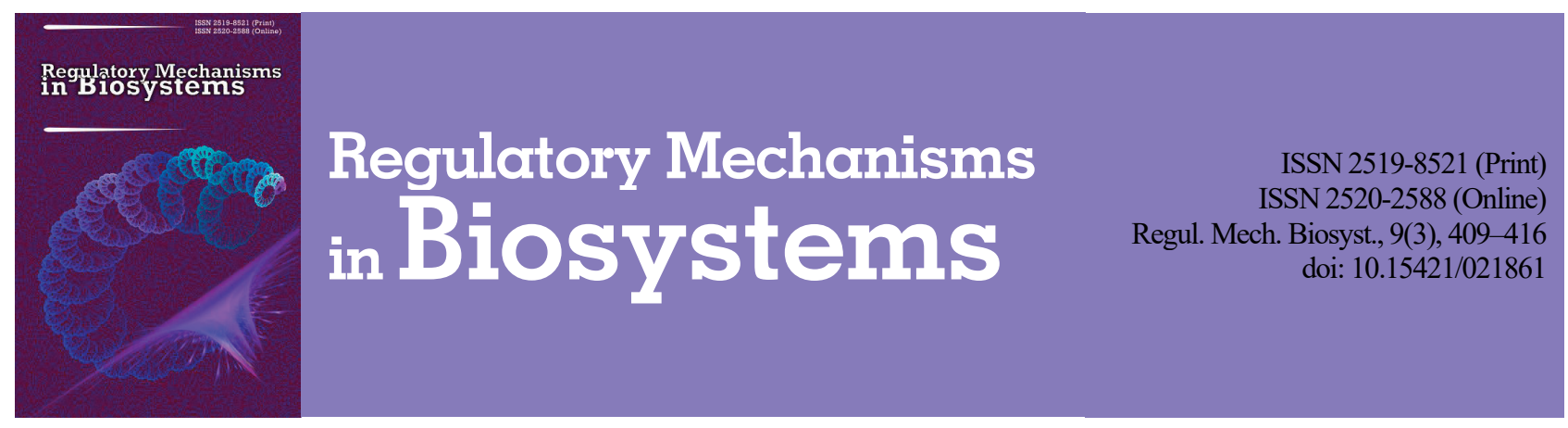

\title{
Comparative analysis of incidence of leptospirosis among farm animals and humans in Ukraine
}

\author{
V. V. Ukhovskyi*, N. B. Vydayko**, G. B. Aliekseieva***, \\ M. V. Bezymennyi*, I. M. Polupan***, I. P. Kolesnikova**** \\ *Institute of Veterinary Medicine of National Academy of Agrarian Sciences of Ukraine, Kyiv, Ukraine \\ **State Institution Ukrainian Center for Diseases Control and Monitoring of the Ministry of Health of Ukraine, Kyiv, Ukraine \\ ***State Scientific Research Institute of Laboratory Diagnostic and Veterinary Sanitary Expertise, Kyiv, Ukraine \\ ****Bogomolets National Medical University, Kyiv, Ukraine
}

Article info

Received 14.06.2018

Received in revised form 21.07.2018

Accepted 28.07.2018

Institute of Veterinary Medicine of National Academy of Agrarian Sciences of Ukraine, Donetska st. 30 Kyiv, 03151, Ukraine. Tel.: +38-067-981-52-26. E-mail:uhovskiy@ukr.net

State Institution Ukrainian Center for Diseases Control and Monitoring of the Ministry of Health of Ukraine, Yaroslavska st., 41, Kyiv, 04071, Ukraine

State Scientific Research Institute of Laboratory Diagnostic and Veterinary Sanitary Expertise, Donetska st., 30, Kyiv, 03151, Ukraine.

Bogomolets National Medical University, T. Shevchenko blvd. 13, Kyiv, 01601, Ukraine.
Ukhovskyi, V. V., Vydayko, N. B., Aliekseieva, G. B., Bezymennyi, M. V., Polupan, I. M., \& Kolesnikova, I. P. (2018). Comparative analysis of incidence of leptospirosis among farm animals and humans in Ukraine. Regulatory Mechanisms in Biosystems, 9(3), 409-416. doi:10.15421/021861

Leptospirosis remains one of the most widespread natural-focal, zoonotic infectious diseases in the world and in Ukraine. Leptospirosis is enzootic in the entire territory of Ukraine. Cases of diseases are registered in all regions of Ukraine. We initiated a study of comparative analysis of territorial distribution of leptospirosis outbreaks among animals and incidence in humans in Ukraine covering the years 2009-2016 inclusive. This study of the incidence of leptospirosis in Ukraine shows a significant circulation of leptospirosis both among humans and animals. Among cattle herds in Ukraine the percentage of positive animals was found to be $4.2 \%$ of the surveyed population. The dominant serovars of Leptospira were kabura (12.4\%) and polonica $(9.5 \%)$. Positive reactions with other serovars were observed less frequently: tarassovi $-5.1 \%$, bratislava $-4.9 \%$, copenhageni$4.1 \%$, grippotyphosa $-2.4 \%$, pomona $-1.1 \%$, canicola $-1.0 \%$. In pigs, the percentage of positive animals amounted to $3.2 \%$, the dominant serovars of Leptospira were bratislava (29.1\%) and copenhageni (25.1\%). Positive reactions with other serovars were observed less frequently: tarassovi $-4.3 \%$, canicola $-3.0 \%$, pomona $-2.7 \%$, grippotyphosa $-1.3 \%$, polonica $-1.2 \%$, kabura $0.6 \%$. In horses, the percentage of positive animals amounted to $9.5 \%$ of the surveyed population. The serological range of Leptospira in horses was as follows: copenhageni $-14.2 \%$, bratislava $-12.1 \%$, canicola $-6.8 \%$, grippotyphosa $-4.8 \%$, tarassovi $-4.7 \%$, pomona $-2.1 \%$, kabura $-1.4 \%$, polonica - $1.3 \%$. Analysis of the results of research indicates extensive circulation of leptospirosis among humans in Ukraine as evidenced by the percentage of humans positively responding to MAT - $12.1 \%$ of the studied samples. The etiological structure of leptospirosis cases includes all the 14 serovars of the diagnostic set. The basis of the etiological spectrum was the serovar copenhageni-37.3\%. The share of other serovars as the etiological factor of leptospirosis in humans was different in different spans of the considered period. Most frequently, those were kabura - 12.3\%, grippotyphosa$11.7 \%$, canicola $-9.5 \%$, pomona $-9.1 \%$. We mapped annual incidence of leptospirosis in animals and humans. Choropleth maps of annual leptospirosis incidence and cluster maps show opposite spatial patterns for animals and humans. The highest human rates were in the western and central parts of the country while the highest animal rates were mainly in the eastern part.

Keywords: Leptospira; etiological structure; microscopic agglutination test; mapping; GIS.

\section{Introduction}

Leptospirosis is an infectious disease that affects a large number of mammal species, as well as humans (Ko et al., 2009; Sykes et al., 2011). It has become widespread in many countries around the world (Levett, 2001; Lee et al., 2017; Daud et al., 2018). Leptospirosis is one of the most common and significant natural foci zoonoses and has been diagnosed on five continents (except Antarctica) in most countries of the world (Bharti et al., 2003). Leptospirosis causes huge economic losses in animal husbandry because of its significant incidence among animals, leading to mass abortions and a large number of still births, a decrease in animal productivity, and significant costs incurred in diagnostic research, treatment and prophylactic and quarantine measures (Hartskeerl et al., 2011; Pavlenko et al., 2011). Leptospirosis is a disease of great social significance because leptospirosis infected animals and host animals pose a direct threat to public health, characterized by high mortality of patients in recent years (Santos et al., 2018). Leptospirosis has been reported in over 150 mammalian species (Malalana et al., 2017; Brown et al., 2018; Miyama et al., 2018). In addition, antibodies against Leptospira strains can be identified in the blood sera of reptiles and amphibians (Levett, 2001; Adler \& Moctezuma, 2010). Among farm animals, this zoonosis is often registered in cattle (Alonso-Andicoberry et al., 2001; Talpada et al., 2008), swine (Hartleben et al., 2013; Pyskun et al., 2016; Bertelloni et al., 2018) and horses (Brem et al., 1999; Arent \& Kędzierska-Mieszkowska, 2013; Arent et al., 2016) throughout the world.

The majority of the leading specialists in the study of leptospirosis have studied the etiological structure of the disease, which of course, requires the constant monitoring both farm animals and dogs, synanthropic rodents and residents of natural foci (Stepna et al., 2016). At this stage, one of the main tasks of epidemiological and epizootic monitoring of natural focal infections is to determine enzootic areas of circulation of pathogens, including leptospirosis (Pavlenko et al., 2011).

Analyses of pathogenic Leptospira isolated in different countries shows that the etiological structure of leptospirosis in specific areas (dis- 
tricts, regions, and countries) is heterogeneous in the number of various serotypes of Leptospira, and their ratios. The objective of our study was comparative analysis of the territorial confines of leptospirosis outbreaks among animals and its incidence in humans in Ukraine.

\section{Materials and methods}

Analysis of the etiological structure of leptospirosis based on data from animals. The spread and etiological structure of leptospirosis in animals was analyzed according to reports of the State Scientific Research Institute of Laboratory Diagnostics and Veterinary Sanitary Expertise during the years 2009-2016. Sero-prevalence for each region was calculated as the number of leptospirosis positive samples divided by the sample quantity in the region. Calculation of exact binomial $95 \%$ confidence intervals (BCI) was performed for sero-prevalence estimates using the R epitools package (https://cran.r-project.org).

Antigens. Cultures of reference strains of Leptospira consisting of 8 serovars: canicola, grippotyphosa, kabura, copenhageni, pomona, polonica, tarassovi and bratislava, were used to perform the microscopic agglutination test (MAT). These diagnostic strains of Leptospira used in serological studies on leptospirosis of animals were prepared by veterinary diagnostic laboratories in Ukraine. Leptospirae were cultivated in Korthof liquid medium at $28-30^{\circ} \mathrm{C}$ under aerobic conditions. The strains were subcultured every 7-10 days.

Microscopic agglutination test. The test was carried out according to OIE Manual of Standards for Diagnostic Tests and Vaccines and under the current Regulations (Nastanova z laboratornoi diahnostyky leptospirozu [Guidance on laboratory diagnosis of leptospirosis]. (1997). Zareiestrovana 11.01.1997, No 15-14/2. Ministerstvo Silskoho Hospodarstva i Prodovolstva Ukrainy, Kyiv). Briefly, the serum samples diluted $1: 25$ were mixed with an equal volume of each of the Leptospira culture. Serum dilution (including added antigen) used during preliminary examination was $1: 50$. For samples reacting in the preliminary examination with one or more serovars, series of twofold dilutions were prepared to reach the end point - 50\% agglutination. The samples with titers equal or higher than $1: 50$ were recognized as positive.

Analysis of etiological structure of leptospirosis based on human data. Spreading and etiological structure of leptospirosis in humans and annual human incidence data per 100,000 population was analyzed according to reports of the State Institution Ukrainian Center for Diseases Control and Monitoring of the Ministry of Health of Ukraine during the years 2009-2016s.

Antigens. Cultures of reference strains of Leptospira consisted of 14 serovars: canicola, grippotyphosa, kabura, copenhageni, pomona, polonica, tarassovi, bratislava, javanica, autumnalis, djatzi, ballum, pyrogenes and cynopteri, were used to perform the MAT. These diagnostic strains of leptospires are used in serological studies on leptospirosis of animals that are conducted by the State Institution Regional Laboratory Center Ministry of Health of Ukraine.

Microscopic agglutination test. The test was carried out under the current Regulations (Protyepidemichni zakhody ta laboratorna diahnostyka leptospirozu. Metodychni vkazivky. MV 9.1.109-02 [Antiepidemic measures and laboratory diagnostics of leptospirosis. Methodological instructions. MI 9.1.109-02]. (2002). Zatverdzhena 11.12.2002, No 39, Kyiv). The serum samples diluted $1: 50$ were mixed with an equal volume of each of the Leptospira serovars. Final serum dilution (including added antigen) during preliminary examination was $1: 100$. For samples reacting in the preliminary examination with one or more serovars, a series of twofold dilutions were prepared to reach the end point $-50 \%$ of agglutination. The samples with titers equal or higher than $1: 100$ were recognized as positive.

Mapping and spatial analysis. Data on the incidence of leptospirosis in animals and humans in three regions for 2014-2016 were not available (AR Crimea, part of the Luhansk and Donetsk regions) and thus they were not mapped.

To calculate annual incidence per 100,000 animals, population data from the web site (www.ukrstat.gov.ua) of the State Statistics Service of Ukraine were used. The data on all three farm animal species (cattle, swine, horses) were summarized.
Annual incidence by region of both animals and humans was choropleth mapped in ESRI ArcGIS 10.3. Quantile classification with 5 classes of the data was chosen. With this classification, an equal number of regions fall into each class.

To find out and compare the patterns of incidence distribution among animals and humans at the regional level, we applied the local Moran I statistics at a statistical significance $\mathrm{P}<0.05$ using 999 permutations in the software GeoDa 1.10.0.8. In the analysis, we applied the first order rook contiguity matrix, where the regions adjoining their boundaries are considered neighbours. Local Moran I statistics reveals both clusters of similar values, and areas dissimilar to their neighbours spatial outliers. On the maps B, areas with a high incidence rate, surrounded by high-value areas are designated High-High, areas with a low value surrounded by areas with a low values - Low-Low. Areas with a high incidence of disease surrounded by neighbours with low values are designated High-Low, areas with a low incidence rate surrounded by high values are Low-High.

\section{Results}

During the years 2009-2016, 1,238,876 samples of cattle sera were investigated by veterinary diagnostic laboratories of Ukraine and 52,310 reacted positive for leptospirosis. Analysis of the results indicates extensive circulation of leptospirosis among cattle herds in Ukraine as evidenced by the percentage of cattle positively responding to MAT, which is $4.2 \%$ (BCI, $4.2-4.3 \%$ ) of the studied samples.

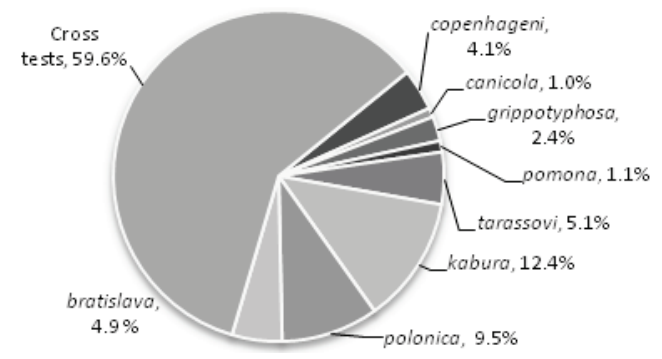

Fig. 1. Etiological structure of leptospirosis in cattle in Ukraine (2009-2016 years)

As shown in Figure 1 the dominant serovars of Leptospira were kabura (12.4\%; BCI, 12.1-12.7\%) and polonica (9.5\%; BCI, 9.29.7\%). Positive reactions with other serovars were observed less frequently: tarassovi - 5.1\% (BCI, 4.9-5.3\%), bratislava - 4.9\% (BCI, 4.7$5.1 \%$ ), copenhageni - 4.1\% (BCI, 4.0-4.3\%), grippotyphosa - $2.4 \%$ (BCI, 2.3-2.6\%), pomona - 1.1\% (BCI, 1.0-1.2\%), canicola - 1.0\% (BCI, 0.9-1.0\%). The proportion of the cattle disease cases where antibodies to multiple serovars of Leptospira (cross tests) were detected was $59.6 \%$ (BCI, 58.9-60.2\%).

During this period, 989,659 samples of pigs' sera were tested by veterinary laboratories in Ukraine and 31,181 samples were regarded as positive for leptospirosis, which amounted to 3.2\% (BCI, 3.1-3.2\%) of the surveyed population.

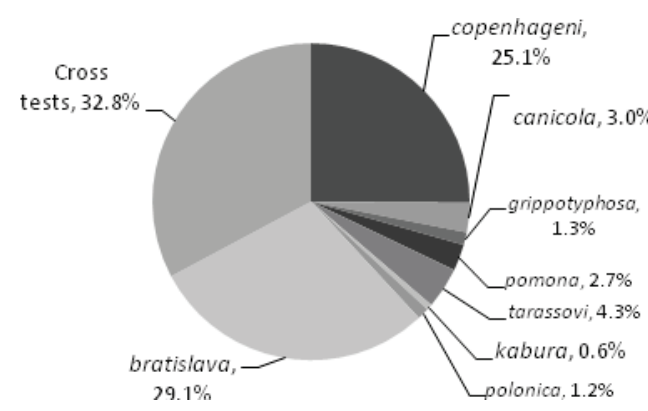

Fig. 2. Etiological structure of leptospirosis in pigs in Ukraine (2009-2016 years)

As shown in Figure 2, the dominant serovars of Leptospira were bratislava (29.1\%; BCI, 28.5-29.7\%) and copenhageni (25.1\%; BCI, 
24.6-25.7\%). Positive reactions with other serovars were observed less frequently: tarassovi $-4.3 \%$ (BCI, $4.0-4.5 \%$ ), canicola $-3.0 \%$ (BCI, 2.8-3.2\%), pomona - 2.7\% (BCI, 2.5-2.9\%), grippotyphosa - 1.3\% (BCI, 1.2-1.4\%), polonica - 1.2\% (BCI, 1.1-1.4\%), kabura - 0.6\% (BCI, 0.5-0.7\%). The proportion of the pigs' disease cases where antibodies to multiple serovars of Leptospira a (cross tests) were detected was 32.8\% (BCI, 32.1-33.4\%).

During the years 2009-2016, 70,674 samples of sera from horses were examined in Ukraine and 6,734 samples were regarded as positive for leptospirosis. Analysis of the results of testing, indicates extensive circulation of leptospirosis among horses in Ukraine, which amounted to $9.5 \%$ (BCI, 9.3-9.8\%) of the surveyed population.

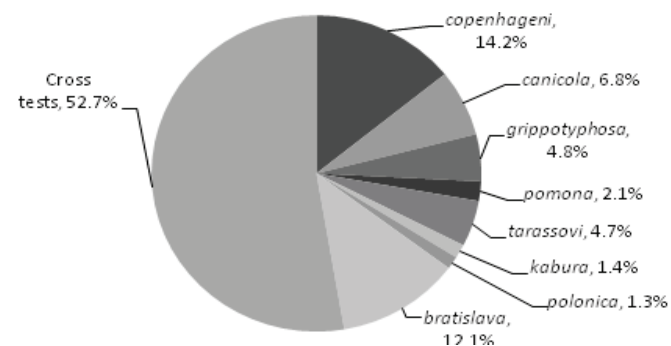

Fig. 3. Etiological structure of leptospirosis in horses in Ukraine (2009-2016 years)

The serological range of Leptospira in horses was as follows: $\mathrm{CO}^{-}$ penhageni - 14.2\% (BCI, 13.3-15.1\%), bratislava - 12.1\% (BCI, 11.3$13.0 \%$ ), canicola - 6.8\% (BCI, 6.2-7.4\%), grippotyphosa - 4.8\% (BCI, 4.3-5.3\%), tarassovi - 4.7\% (BCI, 4.2-5.2\%), pomona - 2.1\% (BCI, 1.7-2.4\%), kabura - 1.4\% (BCI, 1.1-1.7\%), polonica - 1.3\% (BCI, $1.1-1.6 \%$ ). In $52.7 \%$ (BCI, 51.0-54.4\%) of positively reacting sera, antibodies to Leptospira of multiple serovars were detected (Fig. 3).

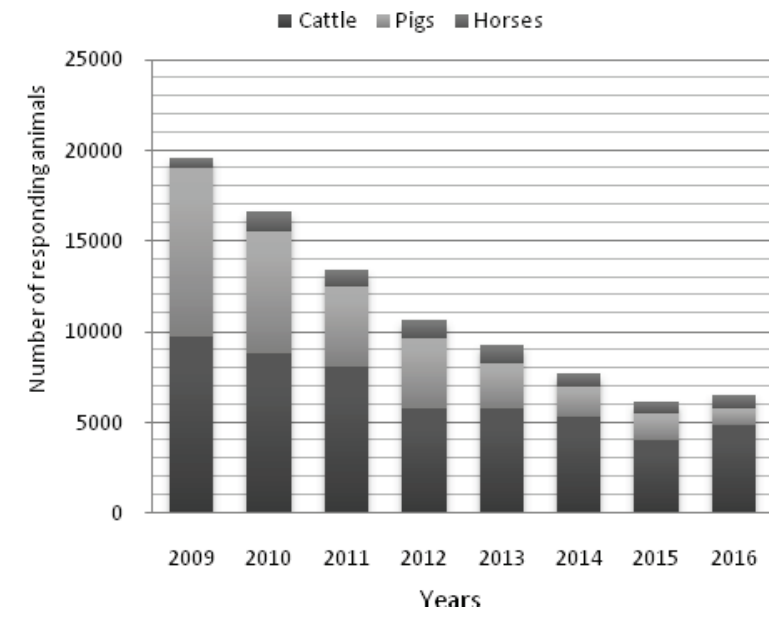

Fig. 4. Dynamics of leptospirosis infection in animals in Ukraine (2009-2016 years)

As shown in Figure 4, leptospirosis infection in animals for the analyzed period was the highest in 2009 - 19,611 positive samples of leptospirosis, the lowest in 2015 - 6,131 positive samples. During the period from 2009 to 2016, there has been a tendency towards reduction in cases of Leptospira infection in animals.

During the years 2009-2016, 24,990 samples of human sera were investigated by the State Institution Ukrainian Centre for Diseases Control and Monitoring of the Ministry of Health of Ukraine and 3,012 samples were regarded as positive for leptospirosis. Analysis of the results of research indicates extensive circulation of leptospirosis among humans in Ukraine as evidenced by the percentage humans of positively responding to MAT, which is $12.1 \%$ (BCI, $11.7-12.5 \%$ ) of the studied samples. The etiological structure of leptospirosis cases included all the 14 serovars of the diagnostic set. As shown in Fig. 5, the basis of the etiological spectrum was the serovar copenhageni - 37.3\% (BCI, 35.2$39.5 \%$ ). The share of other serovars as the etiological factor of leptospirosis in humans was different in different spans of the considered period.
Most frequently, those were kabura - 12.3\% (BCI, 11.0-13.6\%), grippotyphosa - 11.7\% (BCI, 10.5-13.0\%), canicola - 9.5\% (BCI, 8.5-10.7\%), pomona $-9.1 \%$ (BCI, 8.0-10.2\%). Positive reactions with other serovars were observed less frequently: bratislava $-4.4 \%$ (BCI, 3.7-5.2\%), javanica - 4.0\% (BCI, 3.3-4.8\%), autumnalis - 2.7\% (BCI, 2.1-3.3\%), cynopteri - 2.2\% (BCI, 1.7-2.8\%), ballum - 2.1\% (BCI, 1.6-2.6\%), tarassovi-2.0\% (BCI, 1.6-2.6\%), djatzi-1.4\% (BCI, 1.0-1.9\%), pyrogenes$0.8 \%$ (BCI, $0.5-1.2 \%$ ), polonica - 0.6\% (BCI, 0.3-0.9\%) (Fig. 5).

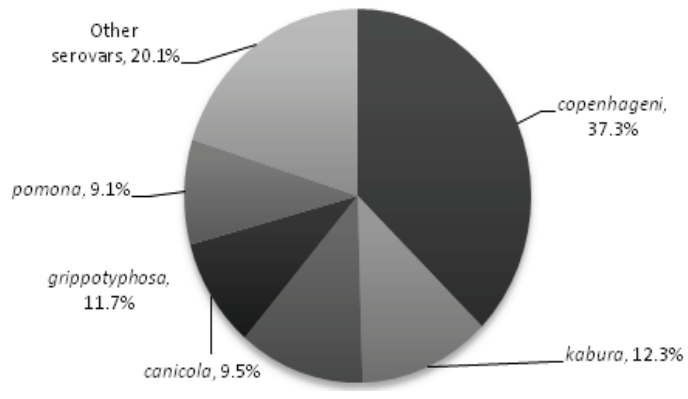

Fig. 5. Etiological structure of leptospirosis in humans in Ukraine (2009-2016 years)

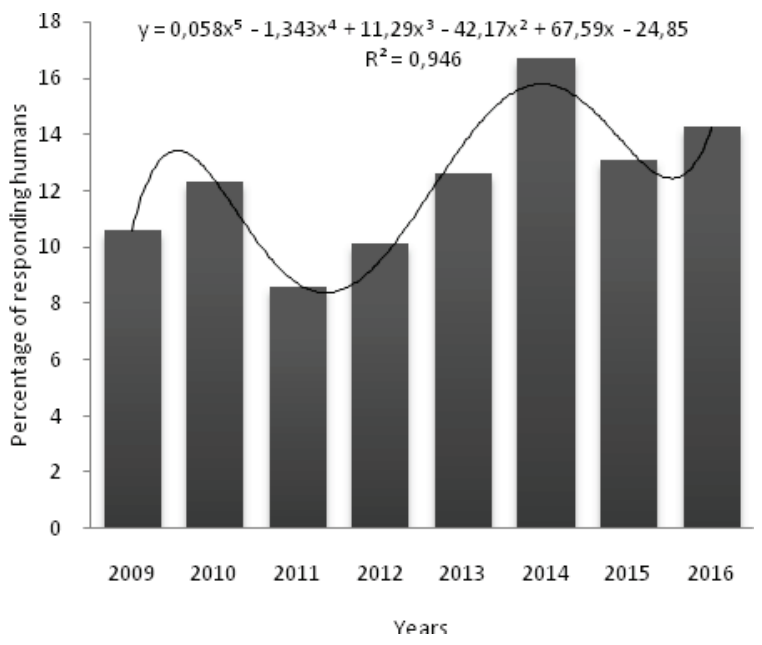

Fig. 6. Dynamics of leptospirosis infection in humans in Ukraine (2009-2016 years)

As shown in Figure 6, leptospirosis infection in humans for the analyzed period was the highest in $2014-16.7 \%$, the lowest in 2011 8.6\% positive samples. During the period from 2009 to 2016, there has been a tendency to increase in cases of leptospirosis infection in humans.

Choropleth maps of annual leptospirosis incidence and cluster maps show opposite spatial patterns for animals and humans (Fig. 7-14). The highest human rates are in western and central parts of the country while the highest animal rates are mainly in the eastern part.

The same opposite pattern was shown by cluster maps. Human High-High clusters are present for 2009-2010 and 2014 in the west. Human Low-Low clusters located in the east over all years but 2016. In 2016 no statistical significant human clusters were revealed.

Animal High-High clusters were found for all years in the east and Low-Low clusters located in western part of Ukraine.

\section{Discussion}

This study shows a significant circulation of leptospirosis both among humans and animals in Ukraine. Among cattle herds, the percentage of reacting positive animals is $4.2 \%$ (BCI, $4.2-4.3 \%$ ), in pigs it amounted to $3.2 \%$ (BCI, 3.1-3.2\%) and in horses it amounted to 9.5\% (BCI, 9.3$9.8 \%$ ) of the surveyed population. Analysis of the results of research indicates extensive circulation of leptospirosis among humans in Ukraine as evidenced by the percentage of positively responding to MAT humans $-12.1 \%$ (BCI, 11.7-12.5\%) of the studied samples. It was established that the epizootic situation concerning animal leptospirosis and 
incidence of leptospirosis in humans in different regions of Ukraine differ both in the etiological structure of agents, and the number of cases. During the analysis of the leptospirosis circulation, we examined for the period 2009-2016 a large number of specimens from animals and people from all over the country: cattle - 1,238,876 samples, pigs - 989,659, horses - 70,674 samples of sera and 24,990 samples of sera of humans.
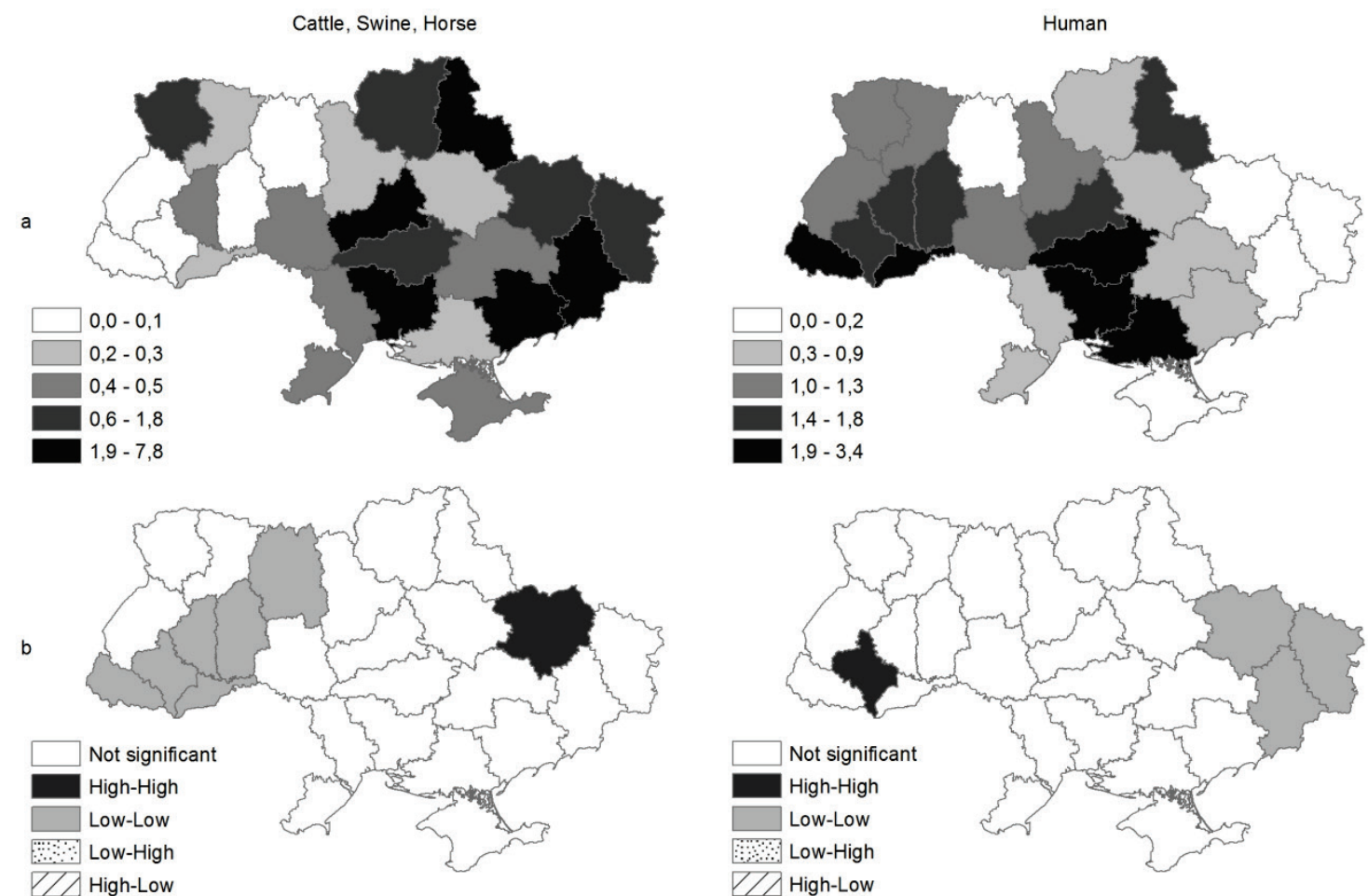

Fig. 7. Distribution of animal and human leptospirosis cases in Ukraine (2009 year): $a$ - animal and human leptospirosis incidence per 100,000 at region level, $b$ - cluster and outlier maps of animal and human leptospirosis incidence
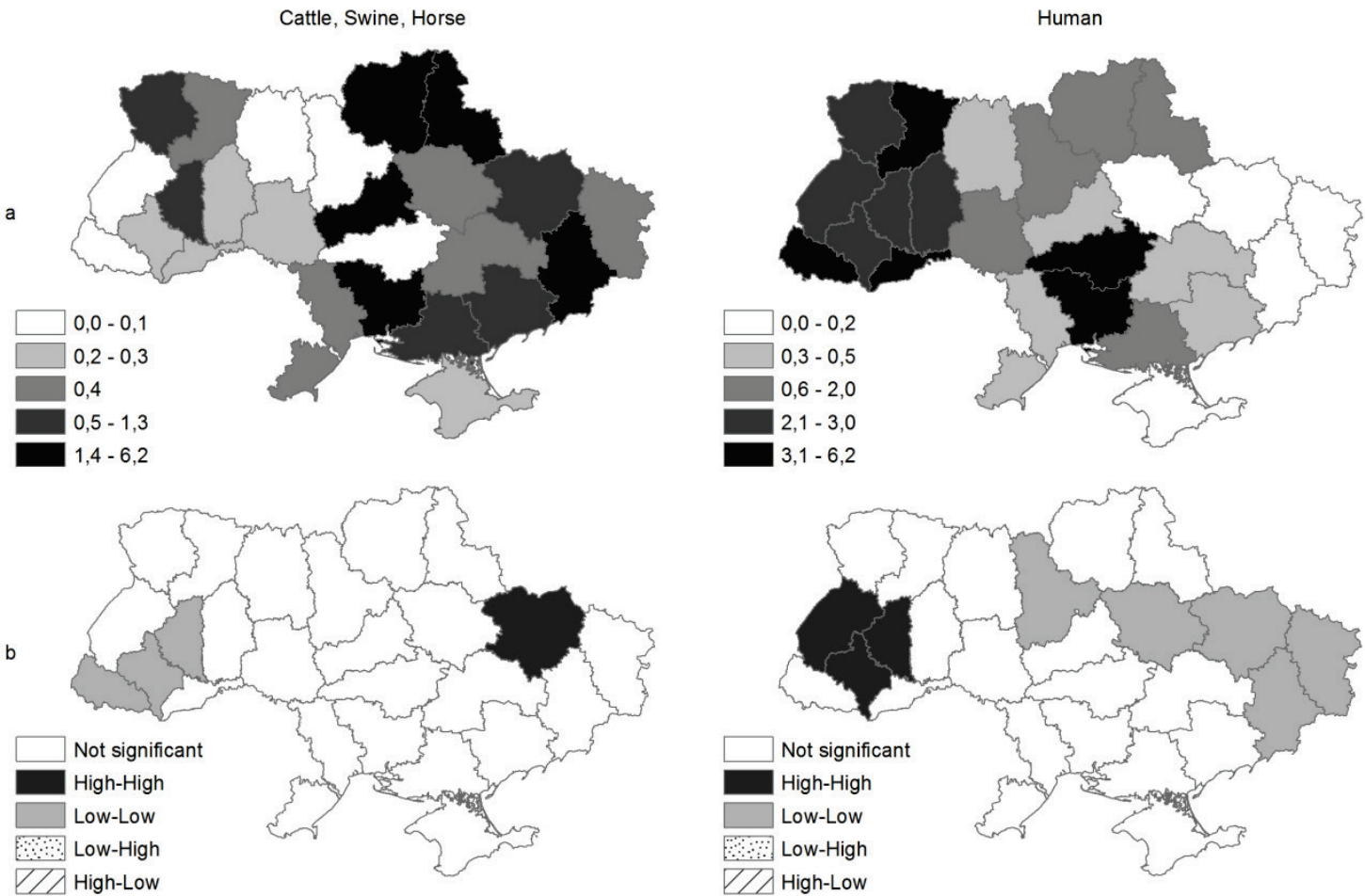

Fig. 8. Distribution of animal and human leptospirosis cases in Ukraine (2010 year): $a$ - animal and human leptospirosis incidence per 100,000 at region level, $b$ - cluster and outlier maps of animal and human leptospirosis incidence 


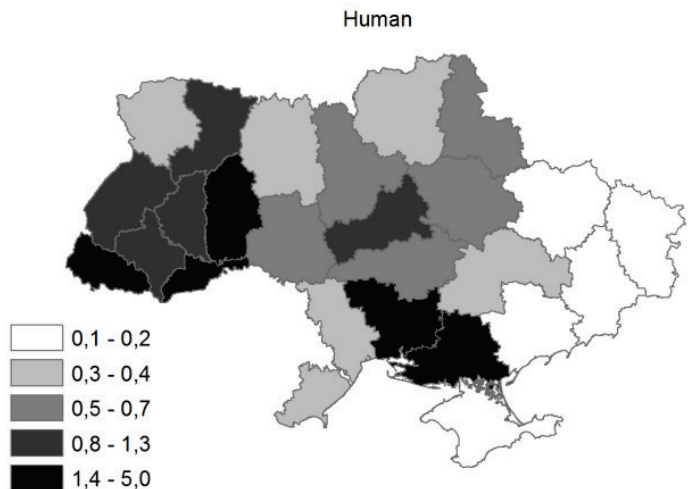

a
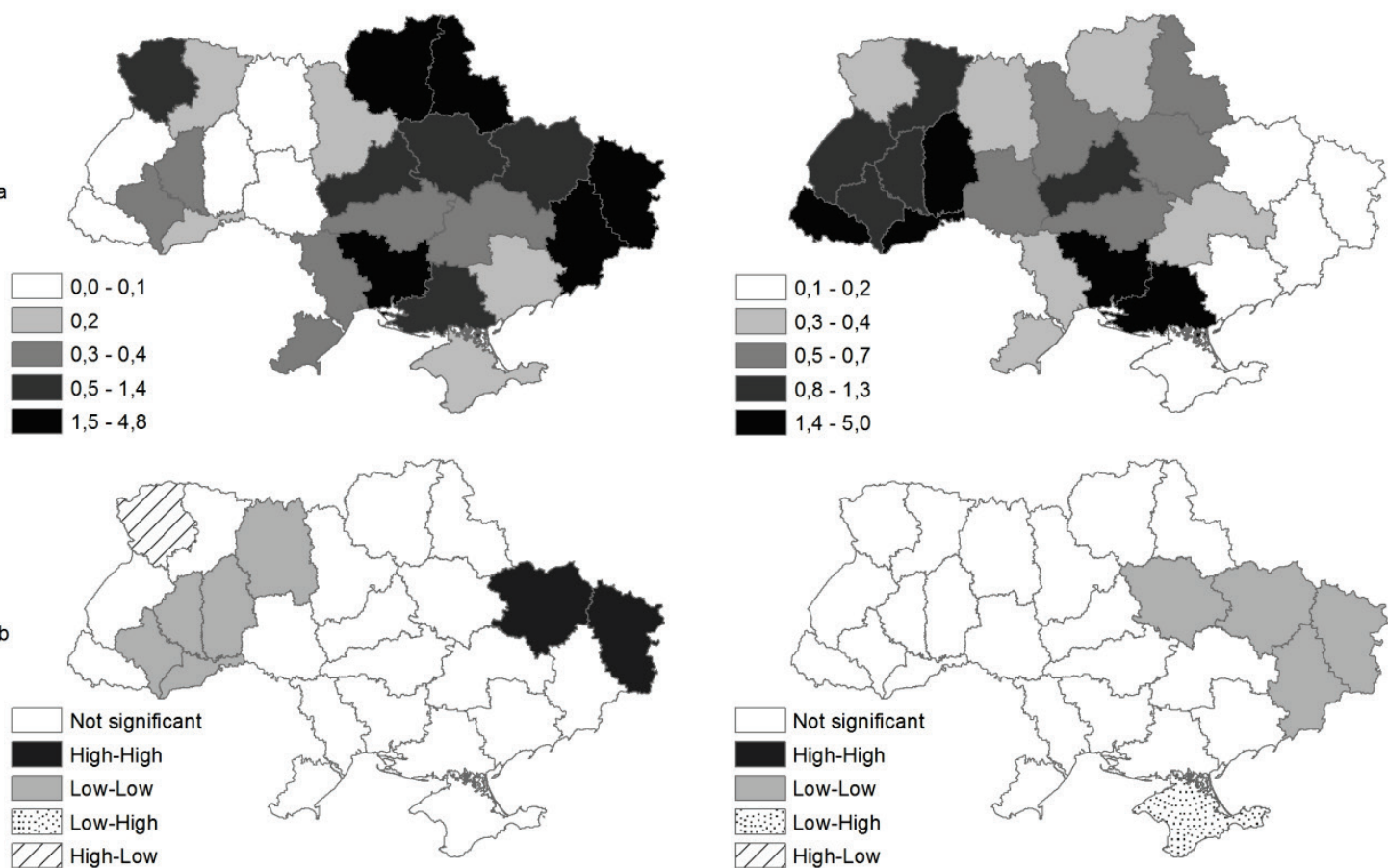

VII High-Low

Fig. 9. Distribution of animal and human leptospirosis cases in Ukraine (2011 year): $a$ - animal and human leptospirosis incidence per 100,000 at region level, $b$ - cluster and outlier maps of animal and human leptospirosis incidence


Fig. 10. Distribution of animal and human leptospirosis cases in Ukraine (2012 year): $a$ - animal and human leptospirosis incidence per 100,000 at region level, $b$ - cluster and outliers maps of animal and human leptospirosis incidence

Regarding the limitations of our research, it should be noted that we did not take into account the distribution and etiological structure of leptospirosis in dogs in Ukraine, since studies of leptospirosis in dogs are conducted mainly on the request of private veterinary clinics, and there is no official state programme for monitoring this disease in dogs. At the same time, leptospirosis in dogs constitutes a significant threat of transmission of leptospirosis to humans (Whitney et al., 2009; Sykes et al., 2011). Leptospirosis is a zoonosis, so cases of this disease in people are observed in areas where there are animals sick with leptospirosis or there are animal hosts (Witkowski et al., 2016; Guernier et al., 2017). Choropleth maps of annual leptospirosis incidence and cluster maps show opposite spatial patterns for animals and humans (Fig. 7-14). The highest human rates are in western and central parts of the country while the highest animal rates are mainly in the eastern part. 
In our opinion, there are two main reasons for the opposite spatial patterns for animals and humans. The first reason is the difference in the causes of the spread of leptospirosis in humans and animals (Flores et al., 2017; Rajala et al., 2017). The most important reasons for the widespread distribution of leptospirosis in animals in Ukraine are inadequate animal welfare, and frequent and uncontrolled movement of them from farm to farm (Malakhov et al., 2000; Sykes et al., 2011). At the same time, natural conditions and rodent population have a secondary role in the occurrence of leptospirosis among animals. In contrast to animals, the main cause of infection in humans are rodents (rats and Cattle, Swine, Horse
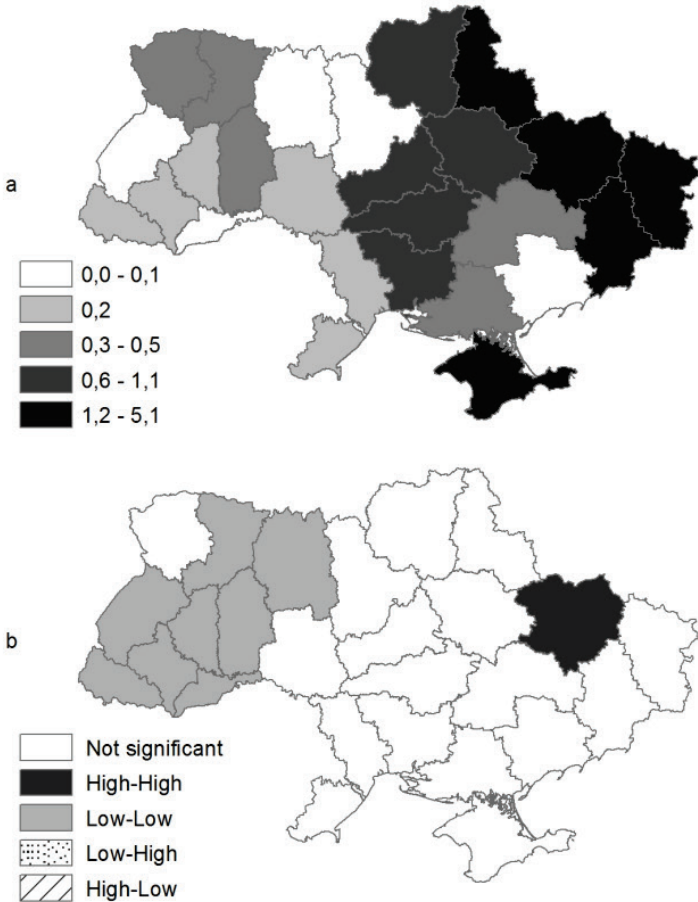

mice) (Stepna et al., 2016; Santos et al., 2018), insufficient rodent control and natural conditions. The main path of infection with Leptospira in Ukraine to humans, in contrast to leptospirosis of animals, is through water (swimming, fishing, working in wet areas, etc.) (Whitney et al., 2009; Barragan et al., 2016; Pinto et al., 2017). The proportion of people with leptospirosis associated with reservoirs and wet places is $50.7 \%$; transmission through food related to the objects of epidemic $-2.2 \%$; contact and household, connected with settlements $-31.9 \%$; not established $-15.2 \%$ (Information report on the epidemic situation with leptospirosis in Ukraine in 2016).

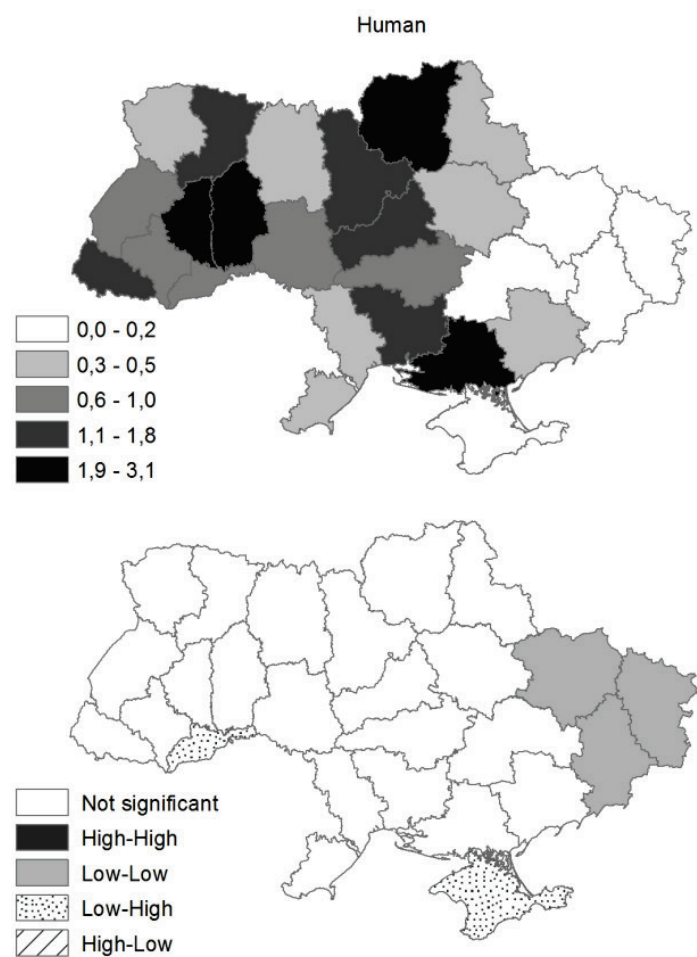

Fig. 11. Distribution of animal and human leptospirosis cases in Ukraine (2013 year): $a$-animal and human leptospirosis incidence per 100,000 at region level, $b$-cluster and outlier maps of animal and human leptospirosis incidence

Cattle, Swine, Horse
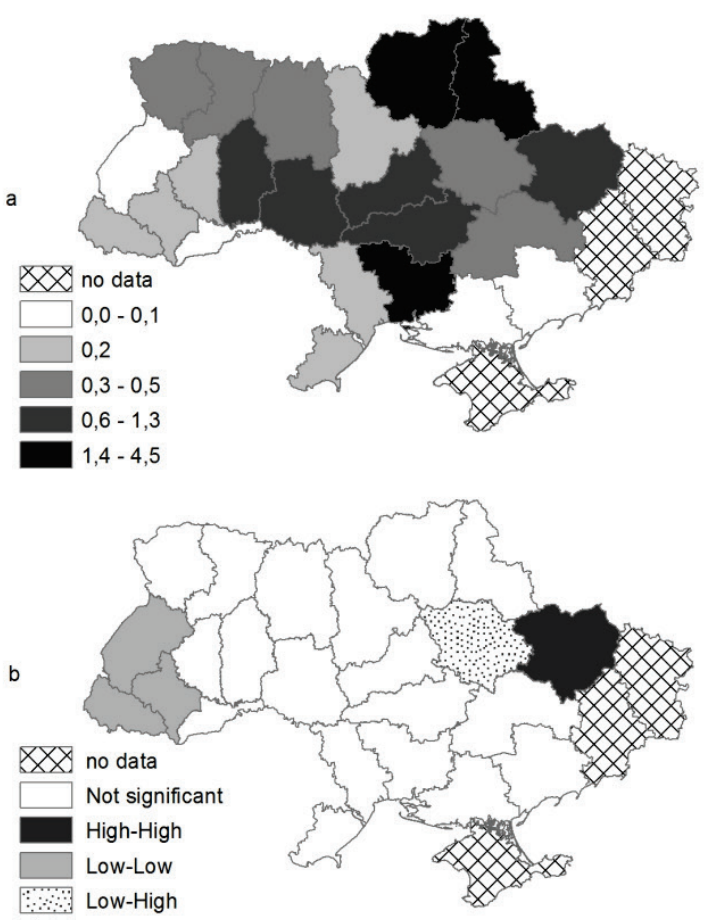
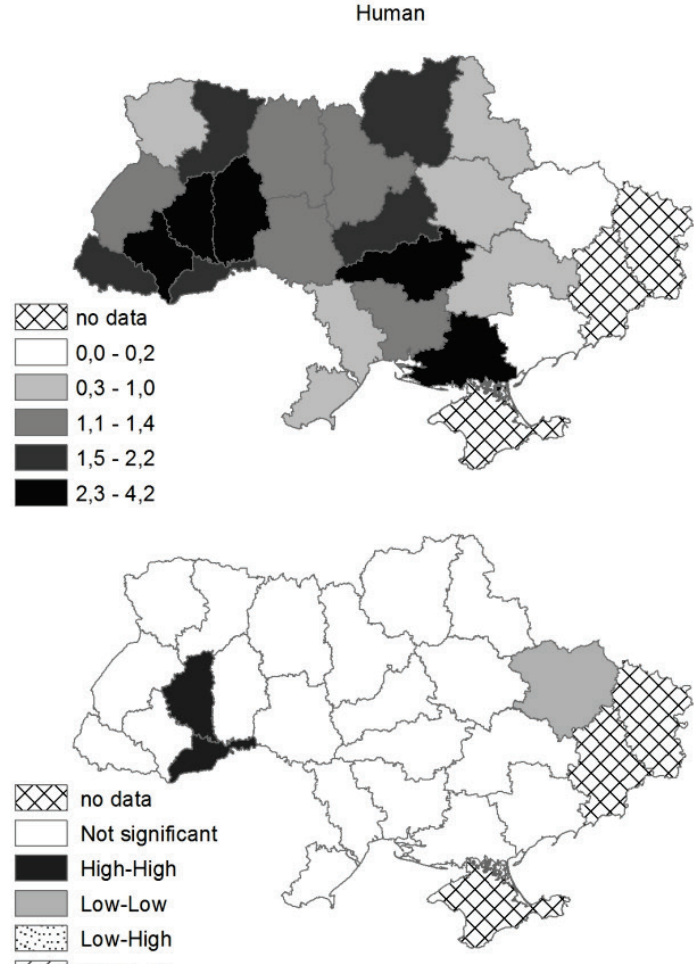

V/ High-Low

V/D High-Low

Fig. 12. Distribution of animal and human leptospirosis cases in Ukraine (2014 year): $a$ - animal and human leptospirosis incidence per 100,000 at region level, $b$ - cluster and outlier maps of animal and human leptospirosis incidence 

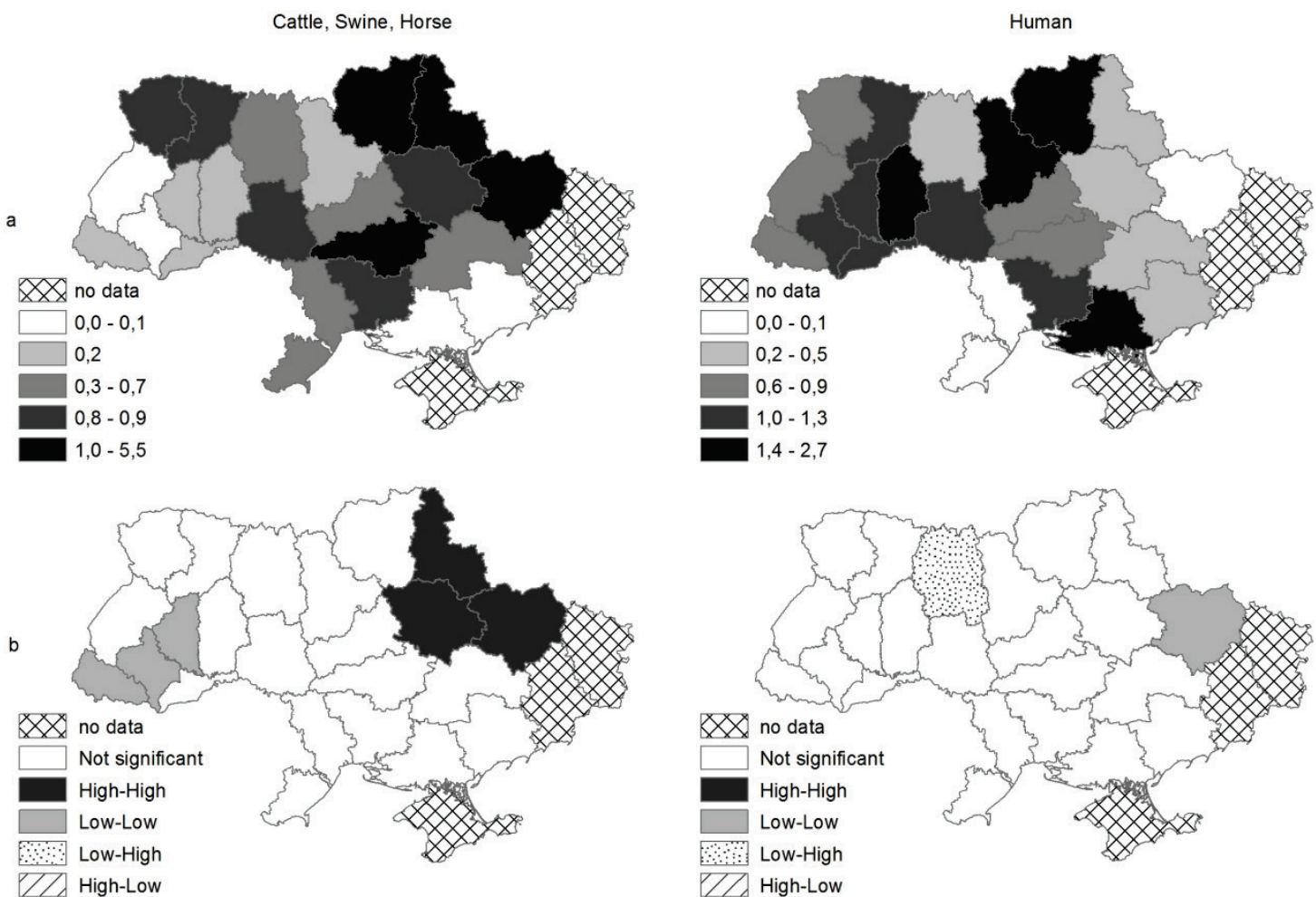

Fig. 13. Distribution of animal and human leptospirosis cases in Ukraine ( 2015 year): $a$ - animal and human leptospirosis incidence per 100,000 at region level, $b$ - cluster and outlier maps of animal and human leptospirosis incidence
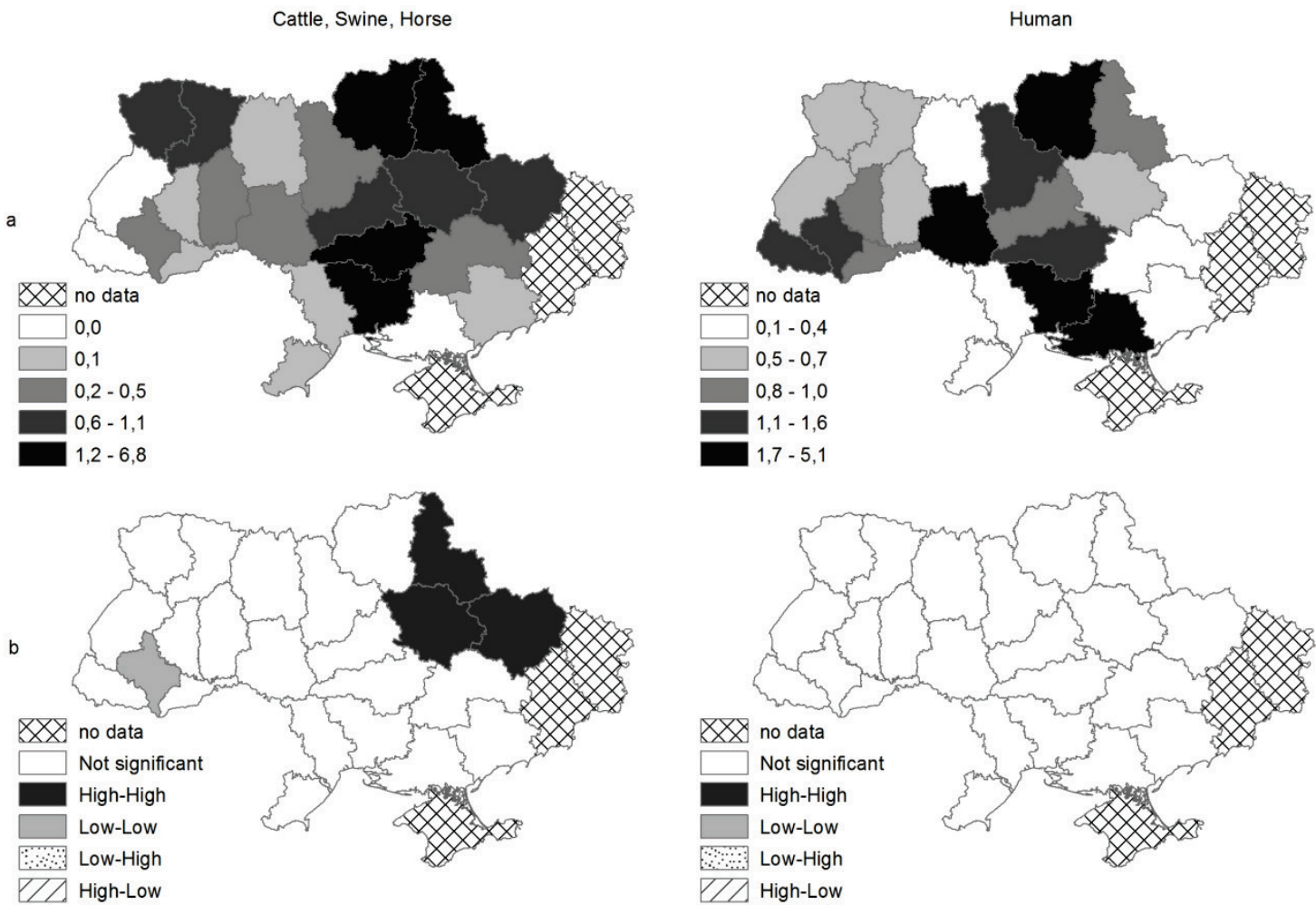

Fig. 14. Distribution of animal and human leptospirosis cases in Ukraine (2016 year): $a$ - animal and human leptospirosis incidence per 100,000 at region level, $b$ - cluster and outlier maps of animal and human leptospirosis incidence

The second reason, in our opinion, is underestimation and possible underreporting of cases in animals and insufficient monitoring of leptospirosis in animals. This applies particularly to the western regions of Ukraine (Ukhovskyi et al., 2015).

\section{Conclusion}

Based on the results of monitoring studies of the territory of Ukraine, we found that leptospirosis is widespread both among livestock and also among people. The average sero-prevalence for 8 years (2009-2016) was: among cattle herds $-4.2 \%$ of the surveyed population, in pigs up to $3.2 \%$, in horses up to $9.5 \%$ and in humans $-12.1 \%$ of the studied samples. It was determined that the spectrum of leptospirosis of agricultural animals and humans in Ukraine had peculiarities both within the range of serovars and their significance for the total pathology of the disease. The dominant serovar Leptospira circulating within the territory of Ukraine were: in cattle - kabura and polonica, in pigs - copenhageni and bratislava, in horses - copenhageni, bratislava and canicola, in 
humans - copenhageni. Based on the results of a comparative analysis of incidence of leptospirosis among farm animals and humans in the territory of Ukraine, it was established that animals and humans manifest opposite patterns. The highest animal leptospirosis rates were detected mainly in the eastern part while the highest human leptospirosis rates were in the western and central parts of the country. This information on the distribution of leptospirosis in animals and humans can help to improve and optimize the planning and development of specific preventive measures against leptospirosis in Ukraine.

\section{References}

Adler, B., \& Moctezuma, A. (2010). Leptospira and leptospirosis. Veterinary Microbiology, 27, 287-296.

Alonso-Andicoberry, C., García-Peña, F. J., Pereira-Bueno, J., Costas, E., \& OrtegaMora, L. M. (2001). Herd-level risk factors associated with Leptospira spp. seroprevalence in dairy and beef cattle in Spain. Preventive Veterinary Medicine, 52(2), 109-117.

Anselin, L. (1995). Local indicators of spatial association - LISA. Geographical Analysis, 27, 93-115.

Arent, Z. J., \& Kędzierska-Mieszkowska, S. (2013). Seroprevalence study of leptospirosis in horses in Northern Poland. Veterinary Record, 172(10), 269.

Arent, Z., Frizzell, C., Gilmore, C., Allen, A., \& Ellis, W. A. (2016). Leptospira interrogans serovars bratislava and muenchen animal infections: Implications for epidemiology and control. Veterinary Microbiology, 190, 19-26.

Barragan, V., Chiriboga, J., Miller, E., Olivas, S., Birdsell, D., Hepp, C., Hornstra, H., Schupp, J. M., Morales, M., Gonzalez, M., Reyes, S., de la Cruz, C., Keim, P., Hartskeerl, R., Trueba, G., \& Pearson, T. (2016). High Leptospira diversity in animals and humans complicates the search for common reservoirs of human disease in rural Ecuador. Neglected Tropical Diseases, 10(9), 49-59.

Bertelloni, F., Turchi, B., Vattiata, E., Viola, P., Pardini, S., Cerri, D., \& Fratini, F. (2018). Serological survey on Leptospira infection in slaughtered swine in North-Central Italy. Epidemiology and Infection, 146(10), 1275-1280.

Bharti, A. R., Nally, J. E., Ricaldi, J. N., Matthias, M. A., Diaz, M. M., Lovett, M. A., Levett, P. N., Gilman, R. H., Willig, M. R., Gotuzzo, E., \& Vinetz, J. M. (2003). Leptospirosis: A zoonotic disease of global importance. Lancet Infectious Diseases, 3, 757-771.

Brem, S., Gerhards, H., Wollanke, B., Meyer, P., \& Kopp, H. (1999). 35 Leptospira isolated from the vitreous body of 32 horses with recurrent uveitis (ERU). Berliner und Münchener Tierärztliche Wochenschrift, 112(10-11), 390-393.

Brown, V. R., Bowen, R. A., \& Bosco-Lauth, A. M. (2018). Zoonotic pathogens from feral swine that pose a significant threat to public health. Transboundary and Emerging Diseases, 65(3), 649-659.

Daud, A., Fuzi, N., Arshad, M., Kamarudin, S., Mohammad, W., Amran, F., \& Ismail, N. (2018). Leptospirosis seropositivity and its serovars among cattle in Northeastern Malaysia. Veterinary World, 11(6), 840-844.

Flores, B. J., Pérez-Sánchez, T., Fuertes, H., Sheleby-Elías, J., Múzquiz, J. L., Jirón, W., Duttmann, C., \& Halaihel, N. (2017). A cross-sectional epidemiological study of domestic animals related to human leptospirosis cases in Nicaragua. Acta Tropica, 170, 79-84.

Guernier, V., Richard, V., Nhan, T., Rouault, E., Tessier, A., \& Musso, D. (2017). Leptospira diversity in animals and humans in Tahiti, French Polynesia. Neglected Tropical Diseases, 11(6), 56-76.

Hartleben, C. P., Leal, F. M., Monte, L. G., Hartwig, D. D., Seixas, F. K., Vasconcellos, S. A., Brihuega, B., \& Dellagostin, O. A. (2013). Serological analysis by enzyme-linked immunosorbent assay using recombinant antigen LipL32 for the diagnosis of swine leptospirosis. Current Microbiology, 66(2), 106-109.
Hartskeerl, R. A., Collares-Pereira, M., \& Ellis, W. A. (2011). Emergence, control and re-emerging leptospirosis: Dynamics of infection in the changing world. Clinical Microbiology and Infection, 17, 494-501.

Ko, A. L., Goarant, C., \& Picardeau, M. (2009). Leptospira: The dawn of the molecular genetics era for an emerging zoonotic pathogen. Nature Reviews Microbiology, 7, 737-747.

Lee, H. S., Khong, N. V., Xuan, H. N., Nghia, V. B., Nguyen-Viet, H., \& Grace, D. (2017). Sero-prevalence of specific Leptospira serovars in fattening pigs from 5 provinces in Vietnam. BMC Veterinary Research, 13(1), 125.

Levett, P. (2001). Leptospirosis. Clinical Microbiology Reviews, 14(2), 296-326.

Malakhov, Y., Panin, A., \& Soboleva, G. (2000). Leptospiroz zhivotnyh [Leptospirosis of animals]. DIA-press, Yaroslavl (in Russian).

Malalana, F., Blundell, R. J., Pinchbeck, G. L., \& Mcgowan, C. M. (2017). The role of Leptospira spp. in horses affected with recurrent uveitis in the UK. Equine Veterinary Journal, 49(6), 706-709.

Miyama, T., Watanabe, E., Ogata, Y., Urushiyama, Y., Kawahara, N., \& Makita, K (2018). Herd-level risk factors associated with Leptospira Hardjo infection in dairy herds in the Southern Tohoku, Japan. Preventive Veterinary Medicine, 149, 15-20.

Pavlenko, A. L., Hajtovich, A. B., Kovalenko, I. S., \& Shvarsalon, N. K. (2011). Ekoregionalnye osobennosti ehnzootichnyh territorij leptospiroza v Ukraine [Ecological end regional features of enzootic areas of leptospirosis in Ukraine]. Profilaktychna Medycyna, 14, 63-69 (in Russian).

Pinto, P. S., Libonati, H., \& Lilenbaum, W. (2017). A systematic review of leptospirosis on dogs, pigs, and horses in Latin America. Tropical Animal Health and Production, 49(2), 231-238.

Pinto, P. S., Pestana, C., Medeiros, M. A., \& Lilenbaum, W. (2017). Plurality of Leptospira strains on slaughtered animals suggest a broader concept of adaptability of leptospires to cattle. Acta Tropica, 172, 156-159.

Pyskun, A. V., Spiridonov, V. G., Ukhovskyi, V. V., Rybalchenko, D. Y., \& Homenko, Y. V. (2016). The validation of enzyme-linked immunosorbent assay for diagnosis leptospirosis among dogs, pigs and cattle. Veterinary Medicine, Biotechnology and Biosafety, 2(1), 11-15.

Rajala, E. L., Sattorov, N., Boqvist, S., \& Magnusson, U. (2017). Bovine leptospirosis in urban and peri-urban dairy farming in low-income countries: A "one health" issue? Acta Veterinaria Scandinavica, 59(1), 83.

Santos, I. O., Landi, M. F., Lima, E. M., Cruz, L. M., Bofill, M. I., Santos, D. E., \& Castro, M. B. (2018). Socio-epidemiological characterization of human leptospirosis in the Federal District, Brazil, 2011-2015. Revista da Sociedade Brasileira de Medicina Tropical, 51(3), 372-375.

Stepna, O., Rodyna, N., Ukhovskyi, V., \& Kulikova, V. (2016). The research of circulation of pathogenic Leptospira among populations urban brown rats in Kyiv, Ukraine. Veterinary Medicine, Biotechnology and Biosafety, 2(1), 5-10.

Sykes, J. E., Hartmann, K., Lunn, K. F., Moore, G. E., Stoddard, R. A., \& Goldstein, R. E. (2011). 2010 ACVIM small animal consensus statement on leptospirosis: Diagnosis, epidemiology, treatment and prevention. Journal of Veterinary Internal Medicine, 25(1), 1-13.

Talpada, M. D., Garvey, N., Sprowls, R., Eugster, A. K., \& Vinetz, J. M. (2003). Prevalence of leptospiral infection in Texas cattle: Implications for transmission to humans. Vector Borne and Zoonotic Diseases, 3(3), 141-147.

Ukhovskyi, V. V., Alekseeva, G. B., Bezymennyy, M. V., \& Kulykova, V. V. (2015). Analysis of the circulation of pathogens on leptospirosis in catle in Ukraine using GIS-technology. Veterinary Biotechnology, 26, 250-262.

Whitney, E. A., Ailes, E., Myers, L. M., Saliki, J. T., \& Berkelman, R. L. (2009). Prevalence of and risk factors for serum antibodies against Leptospira serovars in US veterinarians. Journal of the American Veterinary Medical Association, 234(7), 938-944.

Witkowski, L., Cywinska, A., Paschalis-Trela, K., Crisman, M., \& Kita, J. (2016). Multiple etiologies of equine recurrent uveitis - A natural model for human autoimmune uveitis: A brief review. Comparative Immunology, Microbiology and Infectious Diseases, 44, 14-20. 